\title{
Determinants of emotional problems and mood disorders in women with polycystic ovary syndrome
}

\author{
Aleksandra Głowińska', Monika Zielona-Jenek², Adam Pawelczyk³ , Beata E. Banaszewska \\ 'Department of Psychology, Gynecological and Obstetrical Clinical Hospital, Poznan University of Medical Sciences, Poznan, Poland \\ ${ }^{2}$ Department of Social and Clinical Sexology, Institute of Psychology, Adam Mickiewicz University, Poznan, Poland \\ ${ }^{3}$ Department of Obstetrics, Gynecology, and Gynecological Oncology, Division of Infertility and Reproductive Endocrinology, \\ Department of Gynecology/Obstetrics, Poznan University of Medical Sciences, Poznan, Poland
}

\begin{abstract}
Objectives: The aim of the study was to assess the prevalence and severity of emotional problems among Polish women with polycystic ovary syndrome (PCOS) and seek factors which increase the risk of their occurrence.

Material and methods: The study group consisted of 82 women (aged 18-48), who were diagnosed with PCOS based on the Rotterdam criteria. During hospitalization, the patients completed a number of questionnaires, providing their sociodemographic data and information concerning the inconvenience of disease-associated symptoms. The questionnaires included the Beck Depression Inventory (BDI), State-Trait Anxiety Inventory (STAI), and Multidimensional Self-Esteem Inventory (MSEI). Data obtained during medical examinations (blood tests, transvaginal ultrasound, height and body mass measurements) were analyzed.

Results: Out of 82 women, the results detected risk for depression in 42 (51.22\%), mild depressive disorders in 32, moderate disorders in 8 , and severe disorder in 2 patients. No statistically significant correlation between BDI or state anxiety and the level of the analyzed hormones, insulin resistance, or infertility treatment, was found. General self-esteem, trait anxiety, and marital status were associated with the occurrence of depression symptoms. BMI was associated with the level of state anxiety during hospitalization.

Conclusions: Women with PCOS are at risk for mood and anxiety disorders. Disease-related somatic factors are not directly associated with the risk for disorder occurrence. However, severity of depression symptoms has been shown to be influenced by permanent psychological characteristics of the studied women, i.e. self-esteem, trait anxiety, and life situation (marital status). Therefore, it is recommended to include interviews about patient life situation and screening questionnaires for assessing depression into the diagnostic procedures in PCOS patients. Patients should be referred for a psychological or psychiatric consultation, if needed.
\end{abstract}

Key words: polycystic ovary syndrome, PCOS, mood disorders, anxiety, depression

Ginekologia Polska 2016; 87, 6: 405-410

\section{INTRODUCTION}

Polycystic ovary syndrome (PCOS) is the most common endocrinopathy, affecting women in the reproductive age. PCOS is diagnosed in approximately $5-10 \%$ of the female population. The diagnostic criteria include hyperandrogenism, ovulatory disorders, and the presence of ovarian cysts on ultrasound. Diversity of the diagnostic criteria results in a significant patient heterogeneity in terms of concomitant symptoms such as hirsutism, acne, excess weight, or obesity. Due to its complex nature, PCOS may be accompanied by a number of problems, manifesting over the course of a patient's life and causing considerable stress. PCOS is treated as a risk factor for infertility, metabolic syndrome, and cardiovascular diseases. Prospective studies in perimenopausal women with PCOS have demonstrated higher incidence of type II diabetes [1-5]. According to various authors, PCOS patients are more likely to suffer from mood disorders and increased anxi- 
ety [6-9]. Most studies on the mental functioning of the affected women are comparative, estimating the incidence of mood disorders and anxiety level in PCOS patients and healthy controls. The results unequivocally indicate that depressive disorders are 4-5 times more frequent among PCOS patients, and that the vast majority of the investigated women present with mild or moderate symptoms of depression and slightly elevated anxiety levels. The main cause behind this remains unclear $[10,11]$, with androgen levels, hirsutism, obesity, insulin resistance, and infertility among the suggested reasons. Interestingly, obesity and infertility treatment, which have been identified as strong risk factors for depression in studies unrelated to PCOS, do not appear to differentiate the group of PCOS patients in terms of risk for mood disorders, according to preliminary reports [12]. A recent study conducted on a relatively large sample of women $(n=301)$ has reported the suspected role of insulin resistance as a risk factor for depression in PCOS patients. However, the results are not consistent with previous publications [13]. Reports evaluating the influence of the body mass index (BMI) on the risk for depression also present conflicting results $[14,15]$. Several studies on the quality of life in PCOS patients have been published. Their results led us to believe that factors influencing the risk for mood disturbance and anxiety in the context of PCOS symptoms may include patient resources, i.e. internal mental disposition as well as environmental support $[16,17]$. Concurrent analysis of the relevant medical and psychological factors and an attempt to describe the mechanisms of developing mood and anxiety disorders in PCOS patients, rather than attempting to identify a single factor, appears to be a promising method.

\section{OBJECTIVES}

The primary aim of the study was to investigate the prevalence and severity of emotional problems (i.e., symptoms of mood disorders and anxiety levels during hospitalization) in Polish women with PCOS. The secondary aim was to explore the promoting factors. Based on the review of the literature, these factors were assumed to include biochemical variables reflecting the status of the somatic disease [BMI, insulin resistance, infertility, levels of testosterone, prolactin, sex hormone binding globulin (SHBG), didehydroepiandrosterone (DHEAS), cortisol] and psychological variables: subjective perception of the disease, self-esteem, and life situation (intimate relationship, children).

\section{MATERIAL AND METHODS Material}

This was a cross-sectional study of PCOS women $(n=82)$, aged 18-48 (mean $=28, S D=5.48)$, diagnosed using the Rotterdam criteria, who were examined between 2012 and
2015 during hospitalization at the Division of Infertility and Reproductive Endocrinology, Department of Obstetrics and Gynecology, Poznan University of Medical Sciences. Written informed consent was obtained and the patients completed the questionnaires. The research presented here is a part of a larger study.

\section{Measures}

Somatic state: data were obtained during medical examination including body mass and height measurements, ovarian ultrasound, and blood tests. The analysis of endocrine markers included the following parameters: testosterone $(\mathrm{ng} / \mathrm{mL})$, DHEAS $(\mu \mathrm{mol} / \mathrm{L})$, prolactin $(\mathrm{ng} / \mathrm{ml})$, $\mathrm{SHBG}(\mathrm{nmol} / \mathrm{L})$, and morning cortisol ( $\mathrm{nmol} / \mathrm{L})$. Insulin resistance was diagnosed using oral glucose tolerance tests. The patients were also asked whether they were undergoing infertility treatment.

Subjective experience of the disorder: A questionnaire concerning the inconvenience of particular PCOS symptoms was used. The symptoms included obesity, hirsutism, infertility, irregular menstrual periods/amenorrhea, acne, seborrhea, alopecia, dark spots on the skin, pelvic pain, strong premenstrual syndrome (PMS). With regard to specific spheres of functioning (professional life, sexuality, social contacts, physical and mental well-being), the patients were asked which symptoms they perceived as the most inconvenient.

Sociodemographic status: The questionnaire included questions about the following sociodemographic data: age, education, place of residence, intimate relationship, duration of the relationship, cohabitation, marital status, children.

Emotional problems: Two measures of emotional disturbances were used: the Beck Depression Inventory (BDI; Beck, 1961; Polish adaptation by Parnowski, Jernajczyk, 1977), and the State-Trait Anxiety Inventory (STAl; Spielberger et al., 1970; Polish adaptation by Spielberger, Wrześniewski et al. 1987) [18, 19].

Self-esteem was evaluated with the Multidimensional Self-Esteem Inventory (MSEl; O'Brien, Epstein, 1988; Polish adaptation by Zawadzki, Strelau et al., 2007) [20].

\section{Statistical analysis}

Descriptive data were evaluated using means (M), standard deviations (SD), ranges, and frequencies. Pearson and Spearman correlation coefficients and partial correlation coefficients as well as multiple regression analysis were used to verify the relationships between the intensity of emotional problems and other variables in the sample. Student's t test was used to compare the continuous variables among the groups. P-value of $<0.05$ was considered as statistically significant. The calculations were performed using IBM Statistics SPSS, version 23.0. 


\section{RESULTS \\ Sociodemographic characteristics and clinical symptoms in the sample}

Patient age was 18-48 years (mean $=28$ years, $\mathrm{SD}=5.48$ years). The majority of the women had secondary or higher education ( $n=77,93.9 \%)$, were in a stable and intimate relationship ( $n=73,89 \%)$, lived together with their partners $(n=59,72 \%)$, and were married $(n=44,53.7 \%)$. Only $15(18.3 \%)$ of the women had children. Detailed characteristics of the sample are presented in Table 1.

\section{Prevalence of depression and anxiety in the sample}

Mean BDI score in the sample was 11.17 (SD $=7.65$, range 0-40). Forty (48.8\%) patients had low BDI scores, indicating lack of depressive symptoms, 32 (39\%) - mild depression, 8 (9.76\%) - moderate (11-27 points), and 2 (2.44\%) had high scores, indicating severe depression ${ }^{1}$. Mean STAI score was 42.88, (SD = 10.35, range 21-69), which corresponded to the STen score of 7, according to the norms described for the Polish population.

\section{Correlations of depression and anxiety in the sample}

Biochemical indicators were not related to depression or state anxiety in the sample (Table 2 ). The only significant relationship was detected between state anxiety and BMI. Neither depression ( $t=-0.197, d f=80, p=0.844$ ) nor anxiety ( $t=0.554, \mathrm{df}=64,483, \mathrm{p}=0.581$ ) were related to insulin resistance. Similar findings were revealed for infertility treatment: no differences between the groups in terms of depression were found $(t=0.079, d f=80, p=0.937$ ) or anxiety $(\mathrm{t}=-0.318, \mathrm{df}=45.453, \mathrm{p}=0.752)$.

The patients reported various levels of inconvenience associated with specific PCOS symptoms in their daily lives. The analysis included only those symptoms which were reported by at least $25 \%$ of the studied women. Therefore, data concerning alopecia, seborrhea, pelvic pain, and dark skin spots were not analyzed due to low incidence of these symptoms. Detailed analysis revealed no differences between the level of depression and the reported level of inconvenience associated with obesity, hirsutism, infertility, irregular periods, acne, and prolonged PMS. Higher levels of state anxiety were declared by patients who reported the inconvenience of obesity in their lives. Patients who reported the inconvenience of menstrual disturbances and acne declared lower state anxiety (Table 3). There were no

\footnotetext{
1 The interpretation of $\mathrm{BDI}$ stores was made on the basis of the following intervals: $\leq 9$ points - lack of depressive symptoms, 10-18 points - mild depression, 19-29 points - moderate depression, $>30$ points - severe depression [21]
}

\begin{tabular}{|c|c|}
\hline \multicolumn{2}{|l|}{ Sociodemographic } \\
\hline Age (years)* & $28 \pm 5.48$ \\
\hline Education** & $\begin{array}{l}\text { Primary: } 2 \text { (2.44\%) } \\
\text { Occupational: } 3(3.66 \%) \\
\text { Secondary: } 28(34.15 \%) \\
\text { Higher: } 49(59.75 \%)\end{array}$ \\
\hline Place of residence ${ }^{* *}$ & $\begin{array}{c}\text { Village: } 24(29.3 \%) \\
\text { Town > } 10000: 7(8.5 \%) \\
\text { Town } 10000-100000: 16(19.5 \%) \\
\text { City } 100000-500000: 4(4.9 \%) \\
\text { City < } 500000: 31(37.8 \%)\end{array}$ \\
\hline $\begin{array}{l}\text { Relationship status (stable } \\
\text { and intimate relationship) }\end{array}$ & $\begin{array}{c}\text { No: } 9(11 \%) \\
\text { Yes: } \\
\text { > } 6 \text { months: } 3(3.7 \%) \\
6 \text { months-1 year: } 8(9.8 \%) \\
\text { 1-5 years: } 17(20.7 \%) \\
\text { 5-10 years: } 34(41.5 \%) \\
\text { < } 10 \text { years: } 11(13.4 \%)\end{array}$ \\
\hline Cohabitation** & $\begin{array}{l}\text { No: } 23(28 \%) \\
\text { Yes: } 59(72 \%)\end{array}$ \\
\hline Marital status** & $\begin{array}{c}\text { Single: } 37(45.1 \%) \\
\text { Divorced: } 1(1.2 \%) \\
\text { Married: } 44(53.7 \%)\end{array}$ \\
\hline Children** $^{* *}$ & $\begin{array}{l}\text { No: } 67(81.7 \%) \\
\text { Yes: } 15(18.3 \%)\end{array}$ \\
\hline \multicolumn{2}{|l|}{ Clinical } \\
\hline Testosterone $[\mathrm{ng} / \mathrm{mL}]^{*}$ & $0.47 \pm 0.16$ \\
\hline Prolactin $[\mathrm{ng} / \mathrm{ml}]^{*}$ & $27.45 \pm 19.22$ \\
\hline SHBG $[\mathrm{nmol} / \mathrm{L}]^{*}$ & $55.20 \pm 42.29$ \\
\hline DHEAS [umol/L]* & $8.03 \pm 3.38$ \\
\hline Cortisol $8.00[\mathrm{nmol} / \mathrm{L}]^{*}$ & $507.71 \pm 178.95$ \\
\hline $\mathrm{BMI}^{*}$ & $26.0 \pm 5.30$ \\
\hline Insulin resistance** & $\begin{array}{l}\text { Yes: } 43(52.44 \%) \\
\text { No: } 39(47.56 \%)\end{array}$ \\
\hline Infertility treatment** & $\begin{array}{l}\text { Yes: } 56(68.3 \%) \\
\text { No: } 26(31.7 \%)\end{array}$ \\
\hline
\end{tabular}

*Mean $\pm S D ; *$ number (percent)

Table 2. Relationships between emotional problems and somatic state in the sample (partial correlation coefficients)

\begin{tabular}{|l|c|c|}
\hline & Depression & Anxiety \\
\hline Testosterone & 0.035 (n.s.) & -0.069 (n.s.) \\
\hline Prolactin & -0.196 (n.s.) & -0.035 (n.s.) \\
\hline SHBG & -0.094 (n.s.) & -0.065 (n.s.) \\
\hline DHEAS & -0.116 (n.s.) & -0.040 (n.s.) \\
\hline Cortisol 8.00 & -0.013 (n.s.) & 0.128 (n.s.) \\
\hline BMI & 0.154 (n.s.) & $0.361(p=0.008)$ \\
\hline
\end{tabular}

n.s. - not statistically significant 
Table 3. Declared inconvenience of PCOS symptoms and anxiety in the sample

\begin{tabular}{|l|c|c|c|}
\hline Symptom & $\begin{array}{c}\text { Inconvenience } \\
\text { of the symptom }\end{array}$ & Mean \pm SD & Group differences statistics \\
\hline Obesity & Yes & $46.06 \pm 9.54$ & $\mathrm{t}=3.865, \mathrm{df}=80, \mathrm{p}<0.001$ \\
\hline Irregular menstrual periods/amenorrhea & No & $37.58 \pm 9.68$ & $\mathrm{t}=-2.675, \mathrm{df}=80, \mathrm{p}=0.009$ \\
\hline & Yes & $39.57 \pm 9.52$ & $\mathrm{t}$ \\
\hline Acne & No & $45.55 \pm 10.42$ & $38.55 \pm 10.27$ \\
\end{tabular}

differences between the groups with regard to hirsutism, infertility, and prolonged PMS.

Data were checked for correlations between intensity of the emotional problems and the sociodemographic characteristics of the studied patients. The obtained results showed no significant association between depression and the investigated characteristics: age ( $r=0.005$, n.s. $)$, education ( $r s=-0.164, n . s$.$) , place of residence ( r s=-0.115$, n.s.), intimate relationship and its duration ( $r s=0.029$, n.s.), cohabitation ( $\mathrm{t}=-0.143, \mathrm{df}=80$, n.s.), and having children $(t=-0.043, d f=80, n . s$.$) . Similarly, the reported level of anxi-$ ety was not associated with age $(r=0.183$, n.s.), education ( $r s=0.03, n . s$.$) , place of residence (r s=-0.094, n . s$.$) , intimate$ relationship and its duration ( $\mathrm{rs}=-0.016$, n.s.), cohabitation $(\mathrm{t}=0.762, \mathrm{df}=80$, n.s.), marital status $(\mathrm{t}=-1,773, \mathrm{df}=80$, n.s.), or having children ( $t=-0.974, d f=80$, n.s.).

A statistically significant negative correlation between self-esteem and depression $(r=-0.732 ; p<0.001)$ and state anxiety $(r=-0.511, p<0.001)$ was found. A strong positive relationship was also found between depression and anxiety including both, state anxiety $(r=0.554, p<0.001)$ and trait anxiety $(r=0.736, p<0.001)$.

Correlations between depression level and the relatively permanent characteristics of the studied patients (self-esteem, trait anxiety), as well as a near-significant association with marital status, prompted us to perform multiple regression analysis. The significance of two out of the three investigated predictors of depression (self-esteem and marital status) is presented in Figure 1.

Analysis of the significance of self-esteem and marital status as predictors of depression in PCOS patients indicated that the model was statistically significant $[F(2)=46.128$, $p<0.001]$ and that both predictors explained a total of $56 \%$ of depression level variability. The introduction of the individual disposition to react with anxiety (trait anxiety) as another predictor resulted in a statistically significant $15 \%$ increase in model significance $[F(2,67)=15.67, p<0.001]$.

The model including these three predictors had strong goodness-of-fit $[F(3)=46.918, p<0.001]$ explained $66 \%$ of the variance changes in the level of depression. The values

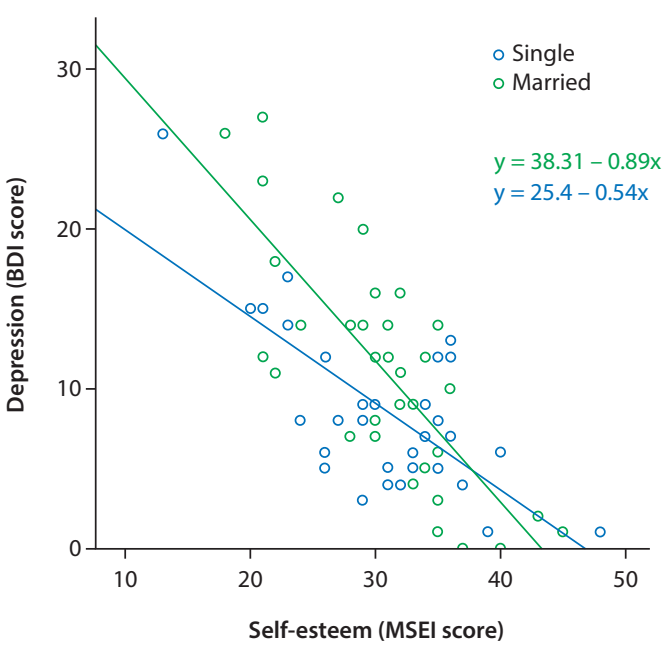

Figure 1. Self-esteem and marital status as predictors of depression in the sample

of standardized beta coefficients for the individual predictors were as follows: self-esteem: $\beta=-0.471, p<0.001$, trait anxiety: $\beta=0.413, p<0.001$, marital status: $\beta=0.159$, $\mathrm{p}=0.026$.

The level of state anxiety declared by the patients was associated with several other groups of variables: BMI, reported inconvenience of PCOS symptoms (obesity, irregular periods, and acne), as well as self-esteem and relatively permanent disposition to react with anxiety (trait anxiety). The results of hierarchical regression analysis conducted for the individual predictors of state anxiety are presented in Table 4. Their comparison led to the conclusion that the strongest predictor, out of the ones included in the individual models, was a permanent disposition of a patient to react with anxiety (Model 4). Trait anxiety enabled to predict $70 \%$ of the variability in the results of patient-reported anxiety; the result abolished the significance of all other previously considered predictors, including self-esteem and the inconvenient disease symptoms.

\section{DISCUSSION}

The emotional state of women undergoing PCOS treatment is important due to its influence on patient motivation, 
Table 4. Multiple regression analysis of predictors of state anxiety in the sample

\begin{tabular}{|c|c|c|c|c|}
\hline & $\begin{array}{l}\text { Significance } \\
\text { of the model }\end{array}$ & Adjusted R square & $\begin{array}{c}\text { Change of significance } \\
\text { of a model statistics }\end{array}$ & Predictors* \\
\hline Model 1 & $F(3)=5.47 ; p=0.002$ & 0.169 & & $\begin{array}{l}\text { Obesity } \beta=0.316 ; p=0.010 \\
\text { Acne } \beta=-0.187 ; n . s \text {. } \\
\text { Irregular periods } \beta=-0.143 ; \text { n.s. }\end{array}$ \\
\hline Model 2 & $F(4)=4.61 ; p=0.003$ & 0.180 & $F(1,62)=1.81 ; p=0.183$ & $\begin{array}{l}\text { Obesity } \beta=0.252 ; n . s \\
\text { Acne } \beta=-0.117 ; \text { n.s. } \\
\text { Irregular periods } \beta=-0.188 ; \text { n.s. } \\
\text { BMI } \beta=0.167 ; \text { n.s. }\end{array}$ \\
\hline Model 3 & $F(5)=8.89 ; p=0.001$ & 0.374 & $F(1,61)=20.29 ; p=0.001$ & $\begin{array}{l}\text { Obesity } \beta=0.174 ; \text { n.s. } \\
\text { Acne } \beta=-0.132 ; n . s \text {. } \\
\text { Irregular periods } \beta=-0.077 ; \text { n.s. } \\
\text { BMI } \beta=0.153 ; \text { n.s. } \\
\text { Self-esteem } \beta=-0.457 ; p<0.001\end{array}$ \\
\hline Model 4 & $F(6)=26.65 ; p=0.001$ & 0.700 & $F(1,60)=67,18 ; p=0.001$ & $\begin{array}{l}\text { Obesity } \beta=0.114 ; \text { n.s. } \\
\text { Acne } \beta=-0.094 ; n . s \text {. } \\
\text { Menstrual disorders } \beta=-0.031 ; n \text {.s. } \\
\text { BMI } \beta=0.086 ; n \text {.s. } \\
\text { Self-esteem } \beta=-0.059 ; n \text {.s. } \\
\text { Trat anxiety } \beta=0.716 ; p<0.001\end{array}$ \\
\hline
\end{tabular}

${ }^{*} \beta$ - standardized beta coefficient

treatment compliance, the risk of secondary development of mental disorders, and the overall life satisfaction. It also affects e.g., interest in sexual activity, thus influencing the effectiveness of infertility treatment $[12,17]$.

Higher manifestation of depression symptoms in PCOS patients in the Polish population, demonstrated in the present study, is relatively pronounced, while remaining similar to the results obtained in other countries [10]. This justifies the use of short screening questionnaires assessing the risk for mood disorders in PCOS patients. In case of results which cause concern, the patient can be referred for a psychiatric or psychological consultation.

Noteworthy, increased BMI and inconvenience of obesity was more often reported among women who declared elevated anxiety levels during the evaluation (including hospital stay). In this context, it is interesting to find no relationship between the severity of depression symptoms or anxiety levels and insulin resistance of the studied women (despite the fact that insulin resistance is largely responsible for obesity problems among PCOS women) [1]. The fact that patients with elevated BMI reacted to the study with anxiety and were more likely to report the inconvenience of this symptom can be interpreted as an effect of impaired neuroendocrine balance and metabolic dysregulation. On the other hand, it can also be understood as a consequence of social exposition during hospitalization and a sense of non-compliance to dietary recommendations or to a broader social requirement to have a slim, athletic body build. The results obtained in this context require further exploration, especially that the observed relationships were largely burdened with a masking influence of individual disposition to react with anxiety. The significance of this issue appears important insofar as its analysis may help identify the factors which intensify the unfavorable emotional condition of a patient during hospitalization in order to employ appropriate diagnostic cooperation and treatment.

None of the studied endocrine factors were associated with increased depression symptoms or anxiety levels. Previous publications also failed to demonstrate a correlation between androgen levels and emotional functioning of the affected patients. However, no relationship with the level of cortisol measured after a night's rest was found in our study group. There is a great amount of evidence for the influence of elevated cortisol levels and the associated functioning of the hypothalamic-pituitary-adrenal axis on the occurrence of depression symptoms [22]. Since high blood cortisol levels are strongly associated with the acute phase of depression, it can be surmised that PCOS patients are more likely to suffer from dysthymic disorders.

The significance of a permanent disposition to react with anxiety, low self-esteem, and being married in terms of increased risk of developing depression symptoms indicates the need for introducing psychological diagnostics and evaluation of individual characteristics and life situation in PCOS patients. The obtained results may indicate that the reasons behind mood disorders and increased anxiety levels are associated more with specific psychological disposition of women affected by a chronic disease and universal stress generated by the inconvenient symptoms and their consequences than with biochemical factors typical for PCOS. The obtained results yet again provoke reflection on the limitations of linear (cause-effect) explanations for 
mental disorders. The abolishment of the discriminatory value of such factors as infertility treatment, cortisol levels, and the inconvenience of hirsutism or acne indicates that the development of depression or anxiety in a group as heterogeneous as PCOS patients can be influenced by numerous factors, the significance of which can be mutually strengthened or abolished. Individual contact, together with the resulting personalized and interdisciplinary diagnosis, seem to offer a chance of identifying patient-specific groups of risk factors for secondary mood disorders associated with PCOS. In turn, this can contribute to selection of the optimal treatment method and improve patient compliance with recommendations.

One limitation of the presented study is the structure of the study group in terms of education and severity of depression symptoms. The vast majority of the investigated women had higher education, and few of them had severe depression symptoms, which means that the results can only be used for similar patient groups. The above suggests that more research on the subject should be conducted among women with lower education and more severe emotional problems.

\section{CONCLUSIONS}

Women with PCOS are susceptible to mood and anxiety disorders. Hyperinsulinemia, hyperandrogenism, levels of cortisol, prolactin, SHGB, and DHEAS, as well as infertility treatment were found to be not associated with depression symptoms and anxiety levels in PCOS patients. Factors including low general self-esteem, intensified permanent tendency to react with anxiety, and being in a formal relationship are associated with worse emotional functioning and higher risk for depression. The results indicate the complexity of the factors associated with depression in these women, justifying the need to screen for depression and to refer patients for psychological or psychiatric consultations if the results are a cause for concern.

\section{REFERENCES}

1. Ożegowska KE, Pawelczyk LA. Rola insuliny i wybranych adipocytokin u pacjentek z zespołem policystycznych jajników (PCOS). Ginekol Pol. 2015, 86 (4), 300-304.
2. Holte J, Bergh T, Berne C, [et al.]. Serum lipoprotein lipid profile in women with the polycystic ovary syndrome: relation to anthropometric, endocrine and metabolic variables. Clin Endocrinol (Oxf). 1994, 41, 463-471.

3. Wild RA, Applebaum-Bowden D, Demers LM, [et al.]. Lipoprotein lipids in women with androgen excess: independent associations with increased insulin and androgens. Clin Chem. 1990, 36 (2), 283-289.

4. Wilding J. Leczenie otyłości. BMJ 1997, 315, 997-1000.

5. Moran L, Misso ML, Wild RA, [et al.]. Impaired glucose tolerance, type 2 diabetes and metabolic syndrome in polycystic ovary syndrome: a systematic review and meta-analysis. Hum Reprod Update. 2010, 16 (4), 347-363.

6. Hollinrake E, Abreu A, Maifeld M, [et al.]. Increased risk of depressive disorders in women with polycystic ovary syndrome. Fertility and Sterility. 2007, 87 (6), 1369-1376.

7. Benson S, Hahn S, Tan S, [et al.]. Prevalence and implications of anxiety in polycystic ovary syndrome: results of an internet-based survey in Germany. Hum Reprod. 2009, 24 (6), 1446-1451.

8. Kerchner A, Lester W, Stuart SP, [et al.]. Risk of depression and other mental health disorders in women with polycystic ovary syndrome: a longitudinal study. Fertility and Sterility. 2009, 91 (1), 207-212.

9. Deeks AA, Gibson-Helm ME, Paul E, [et al.]. Is having polycystic ovary syndrome a predictor of poor psychological function including anxiety and depression? Hum Reprod. 2011, 26 (6), 1399-1407.

10. Dokras A, Clifton S, Futterweit W, [et al.]. Increased Risk for Abnormal Depression Scores in Women With Polycystic Ovary Syndrome: A Systematic Review and Meta-Analysis. Obstetrics \& Gynecology. 2011, 117 (1), 145-152.

11. Dokras A. Mood and anxiety disorders in women with PCOS. Steroids. 2012, 77 (4), 338-341.

12. Tan S, Hahn S, Benson S, [et al.]. Psychological implications of infertility in women with polycystic ovary syndrome. Hum Reprod. 2008, 23 (9), 2064-2071.

13. Greenwood EA, Pasch LA, Shinkai K, [et al.]. Putative role for insulin resistance in depression risk in polycystic ovary syndrome. Fertility and Sterility. 2015, 104 (3), 707-714.e1.

14. Teede H, Deeks A, Moran L. Polycystic ovary syndrome: a complex condition with psychological, reproductive and metabolic manifestations that impacts on health across the lifespan. BMC Medicine. 2010, 8, 41.

15. Jedel E, Waern M, Gustafson D, [et al.]. Anxiety and depression symptoms in women with polycystic ovary syndrome compared with controls matched for body mass index. Hum Reprod. 2010, 25 (2), 450-456.

16. Barnard L, Ferriday D, Guenther N, [et al.]. Quality of life and psychological well-being in polycystic ovary syndrome. Hum Reprod. 2007, 22 (8), 2279-2286.

17. Elsenbruch S, Hahn S, Kowalsky D, [et al.]. Quality of Life, Psychosocial Well-Being, and Sexual Satisfaction in Women with Polycystic Ovary Syndrome. J Clin Endocrinol Metab. 2013, 88 (12), 5801-5807.

18. Parnowski T, Jernajczyk W. Inwentarz Depresji Becka w ocenie nastroju osób zdrowych i chorych na choroby afektywne. Psychiatr Pol. 1977, 11 (4), 417-421.

19. Wrześniewski K, Sosnowski T, Jaworska A, Fecenec D. Inwentarz Stanu i Cechy Lęku STAI. 4th ed. Pracownia Testów Psychologicznych Polskiego Towarzystwa Psychologicznego, Warszawa 2011.

20. Fecenec D. Wielowymiarowy Kwestionariusz Samooceny MSEl Polska adaptacja. Pracownia Testów Psychologicznych, Warszawa 2008.

21. Wciórka J, Pużyński S. Narzędzia oceny stanu psychicznego. In: Rybakowski J, Pużyński S, Wciórka J (eds.). Psychiatria. Podstawy psychiatrii. T. 1. Elsevier Urban \& Partner. Wrocław 2010, 413-476.

22. Hammen C. Depresja. Gdańskie Towarzystwo Psychologiczne. Gdańsk 2006. 